\title{
Can vascular mortality be reliably ascertained from the underlying cause of death recorded on a medical death certificate? Evidence from 2800 adjudicated heart protection study (HPS) deaths
}

William Herrington ${ }^{*}$, Karl Wallendszus, Louise Bowman, Martin Landray, Jane Armitage

From 3rd International Clinical Trials Methodology Conference

Glasgow, UK. 16-17 November 2015

\section{Background}

The validity of certified Underlying Cause of Death (UCD) for trial follow-up is unknown.

\section{Methods}

HPS(1994-2001) flagged participants with UK national mortality registers and collected additional information for clinician adjudication of all reported deaths. Agreement between adjudicated (the gold standard) and certified UCD was assessed by Карра(к) statistics.

\section{Results}

Of 20536 participants, 2835 died during trial follow-up, of whom 2778 (98\%) were recorded by UK mortality registers.

Among these registered deaths, 1260 were adjudicated to coronary heart disease(CHD). Certified UCD agreed with 1152 of these, attributed 108 adjudicated CHD deaths to other causes (including 71 non-vascular causes) and wrongly ascribed 81 non-CHD deaths to CHD ( $\mathrm{k}=0.86,95 \%$ confidence interval 0.84-0.88).

Of the 214 adjudicated stroke deaths, certified UCD agreed with 161 but attributed 53 to other causes and ascribed 26 non-stroke deaths to stroke $(\mathrm{K}=0.78,0.74$ $0.83)$. Of the 60 ischaemic stroke deaths, certified UCD recorded 7 as ischaemic stroke, 29 as unknown stroke and 24 to other causes, resulting in poor agreement $(\mathrm{k}=0.19,0.07-0.31)$. Overall, however, agreement for any vascular death remained good $(\mathrm{k}=0.84,0.82-0.86)$.

In HPS allocation to active treatment reduced vascular deaths by $17 \%(781 / 10269(7.6 \%)$ versus $937 / 10267$

CTSU, Nuffield Department of Population Health, University of Oxford, Oxford, UK
(9.1\%); risk ratio $0.83,0.75-0.91)$. Had follow-up solely relied on certified UCD this result would have been materially unchanged (737(7.2\%) versus $900(8.8 \%)$; risk ratio $0.81,0.74-0.90)$.

\section{Conclusions}

Certified UCD from UK mortality registers appears sufficiently reliable to ascertain vascular deaths, including CHD and stroke deaths considered separately, but additional information is required should the need to differentiate stroke subtypes arise.

Published: 16 November 2015

doi:10.1186/1745-6215-16-S2-P61

Cite this article as: Herrington et al:: Can vascular mortality be reliably ascertained from the underlying cause of death recorded on a medical death certificate? Evidence from 2800 adjudicated heart protection study (HPS) deaths. Trials 2015 16(Suppl 2):P61.

Submit your next manuscript to BioMed Central and take full advantage of:

- Convenient online submission

- Thorough peer review

- No space constraints or color figure charges

- Immediate publication on acceptance

- Inclusion in PubMed, CAS, Scopus and Google Scholar

- Research which is freely available for redistribution 